Ege Tıp Dergisi / Ege Journal of Medicine 2018;57(4):244-246

\title{
Uzun süreli proton pompa inhibitörü kullanımına sekonder gastrik nöroendokrin hiperplazi
}

\author{
Neuroendocrine hyperplasia caused by long term use of proton pump inhibitors \\ Fatma Özge Kayhan Koçak \\ Sercan Sahutoğlu \\ Bahattin Gokdemir \\ Zeliha Fulden Saraç \\ Sevnaz Şahin Selahattin Fehmi Akçiçek \\ Ege Üniversitesi Tıp Fakültesi, İç Hastalıkları Anabilim Dalı, Geriatri Bilim Dalı, İzmir, Türkiye
}

\section{Öz}

Yaşla birlikte epigastrik şikâyetler daha yaygın görülmekte ve bu nedenle proton pompası inhibitörlerine (PPI) yaşlılarda daha sık başvurulmaktadır. PPI tedavisi, zararsız olduğu yönündeki algı nedeniyle uygunsuz doz ve sürede kullanılmaktadır. Uzun süre PPI kullanımına bağı ortaya çıkan sık yan etkiler; enfeksiyonlar (Clostridium difficile enteriti, mikroskobik kolit, toplum kaynaklı pnömoni), sindirim ve emilim bozuklukları (vitamin B12, demir, kalsiyum eksiklikleri, hipofosfatemi, hipomagnezemi), kemik kırıkları, akut interstisyel nefrit, demans, kronik böbrek yetmezliğidir. Bu olguda kronik PPI kullanımının nadir görülen yan etkilerinden biri olan nöroendokrin tümör sunularak uygunsuz ilaç kullanımının sonuçlarına dikkat çekilmek istenmiştir.

Anahtar Sözcükler: Proton pompası inhibitörleri, nöroendokrin tümörler, yaşlı, uygunsuz ilaç reçeteleme.

\begin{abstract}
Abdominal complaints are more common in elderly, therefore the use of proton pump inhibitors (PPI) has increased in the aging population. PPI is prescribed inappropriately, as PPls have long been perceived relatively harmless. Advers risks associated with chronic use of PPI; infections (Clostridium difficile enteritis, microscopic colitis, community-acquired pneumonia), digestive and absorption disorders (vitamin B12, iron, calcium deficiencies, hypophosphatemia, hypomagnesemia), bone fractures, acute interstitial nephritis, dementia, chronic renal disease. In this case, neuroendocrine tumor, which is one of the rare side effects of chronic PPI use, is presented to derive the attention of health professionals, to the impact of inappropriate drug use.
\end{abstract}

Keywords: Proton pump inhibitors, neuroendocrine tumors, elderly, inappropriate prescribing.

\section{Giriş}

Yaşla non-steroid anti-inflamatuvar ilaçların (NSAii), antiagregan ve antikoagulan ilaçların kullanımı artmakta, epigastrik şikayetler daha yaygın görülmektedir. $\mathrm{Bu}$ nedenle proton pompası inhibitörleri (PPI) yaşlıda sık kullanılmakta, başlanan PPI tedavisine yarar/zarar oranı dikkate alınmadan uzun dönem devam edilmektedir.

PPI uygunsuz kullanımı, 8 haftadan uzun ya da endikasyon olmadan kullanılması olarak tanımlanabilir. Özellikle yaşlı hastalarda PPİ uygunsuz kullanımı yaygındır. Bunun başlıca sebepleri; ilaca toleransın iyi olması, düzelen dispeptik şikayetlerin tekrar başlamasından korkulması ve ilaç bırakıldıktan sonraki hafif şikayetlerin bile tolere edilememesi olabilir (1).

Yazışma Adresi: Fatma Özge Kayhan Koçak

Ege Üniversitesi Tıp Fakültesi, İç Hastalıkları Anabilim Dalı, Geriatri Bilim Dalı, İzmir, Türkiye

Makalenin Geliş Tarihi:05.09.2017 Kabul Tarihi: 22.11.2017
Yapılan çalışmalarda uzun dönem (6 aydan fazla) PPi kullanımının, istenmeyen yan etkilere neden olabileceği görülmüştür. Baş ağrısı, ishal, kabızlık, mide bulantısı ve deri döküntüsü gibi kısa süreli yan etkiler yapabilmekle birlikte, uzun dönem kullanımda enfeksiyon (Clostridium difficile enteriti, mikroskobik kolit, toplum kaynaklı pnömoni), sindirim ve emilim bozuklukları (vitamin B12, demir, kalsiyum eksiklikleri, hipofosfatemi, hipomagnezemi), kemik kırıkları, akut interstisyel nefrit, demans, kronik böbrek yetmezliği gibi sorunlara yol açabilmektedir. Kronik PPI kullanımının nadir ama ciddi yan etkilerinden biri de kronik asit süpresyonuna bağlı olarak gastrin seviyesinin yükselmesi sonucu oluşan nöroendokrin hiperplazi/ gastrik nöroendokrin tümör (GNET)'dir (2).

Bu olguda, 12 yıldır PPI kullanan ve endoskopide GNET tip 1 saptanan bir hasta sunulmuştur. Olguyu sunmaktaki amacımız, PPI dahil masum gözüken tüm ilaçların kronik kullanımda beklenmeyen yan etkileri olabileceğine dikkat çekmek ve her muayenede ilaç endikasyonlarının sorgulanması gerektiğini vurgula-maktır. 


\section{Olgu Sunumu}

Yetmiş beş yaşında kadın hasta 2 haftadır halsizlik ve yürümede zorlanma nedeniyle kliniğimize yatırıldı. Sistemik sorgusunda bulantı dışında aktif yakınması yoktu. Hasta, romatoid artrit nedeniyle leflunomid $20 \mathrm{mg}$; atriyal fibrilasyon, koroner arter hastalığı ve kalp yetmezliği nedeniyle amiodaron $100 \mathrm{mg}$, rivaroxaban 15 mg, verapamil $2 \times 120 \mathrm{mg}$, kandesartan / hidroklorotiazid $16 / 12.5 \mathrm{mg}$, furosemid $40 \mathrm{mg}$, spironolakton $25 \mathrm{mg}$, pantoprazol $40 \mathrm{mg}$; hipotiroidi için L-tiroksin $100 \mathrm{mcg}$ kullanmaktaydı. Fizik muayenesinde taşikardi, konjuktivada solukluk ve aort odağında sistolik üfürüm mevcuttu. Halsizlik nedeniyle bakılan laboratuvar tetkiklerinde $\mathrm{Hb}: 5.5 \mathrm{~g} / \mathrm{dL}, \mathrm{MCV}: 78.4 \mathrm{fL}$, Hct: \%16.7, Sodyum: $127 \mathrm{mEq} / \mathrm{L}$, TSH: $24 \mathrm{mIU} / \mathrm{mL}$ dışında patoloji saptanmadı. L-tiroksin dozu arttırıldı. Hipervolemik hiponatremi nedeniyle diüretik tedavi dozu düzenlendi ve anemisine yönelik 2 ünite eritrosit süspansiyonu verildi. Anemi etiyolojisi için gönderilen $\mathrm{LDH}$, vitamin B12, folat, ferritin düzeyleri normal, transferrin satürasyonu (\%7) düşük saptandı. Demir eksikliği anemisi nedeniyle yapılan kolonoskopisi normaldi, endoskopide; fundusta 2-3 mm soluk renkli polipoid lezyon, atrofik korpus gastriti ve eritematöz antral gastrit görüldü. Endoskopik biyopsi sonucu; Helicobacter pylori (-), kronik atrofik gastrit, nöroendokrin hiperplazi, psödopilorik metaplazi (kromogranin a pozitif, sinaptofizin pozitif) olarak raporlandı. GNET tip 1 kabul edilen hastada polip boyutunun $1 \mathrm{~cm}$ 'den küçük ve polip sayısının üçten az olması nedeniyle polipektomi yeterli kabul edildi ve GNET açısından takibe alındı.

Hastadan tıbbi verilerinin yayınlanabileceğine ilişkin yazılı onam belgesi alındı.

\section{Tartışma}

Son 20 yılda iyi etkinlik düzeyi ve güvenli olması nedeniyle PPI kullanımı artmıştır. Hastaneye yatan hastaların \%60'ına yakınında PPI başlanmakta ve \%50 civarında taburculuk reçetelerine de eklenmektedir, fakat hastaların çoğuna tedavinin uygun endikasyonla verilmediği görülmektedir (3). STOPP/START kriterlerinde, dilatasyon gerektiren peptik striktür veya ağır gastroözofagiyal reflüde PPI tedavisi verilmesi ve NSAil kullanan hastalarda peptik ülser ya da gastrointestinal kanama öyküsü varsa PPI eklenmesi önerilmektedir (4). Peptik ülser veya eroziv özofajit tedavisinde tam terapötik dozda PPI tedavisinin 8 haftayı geçmemesi söylenmektedir. Çünkü PPI kullanımı güvenli olmasına rağmen, yaşlıda uygunsuz reçete edilmesi yan etki görülme sıklığını da arttırmaktadır.

PPI hastamızda 12 yıl önce dispeptik şikâyetler için başlanmış, sonrasında antiagregan ve antikoagülan ilaç kullanımı olduğu için devam edilmiş, 4 yıldır yeni kuşak oral antikoagülan (YOAK) kullanmasına rağmen kesilmemiştir. Sonuç olarak 12 yıl PPI kullanıımış ve son
4 yıldır gerek olmamasına rağmen devam edilmiştir. Şimdiye kadar bildirilen olgularda, PPi kullanım öyküsünün hastamızda olduğu gibi 5 yıldan uzun olduğu görülmektedir (2,5,6). Ayrıca 2008 ACCF/ACG/AHA kılavuzlarında gastroprotektif tedavi önerilen antikoagülan ilaçların içinde YOAK bulunmamakta ve YOAK ilişkili gastrointestinal kanamaları önleme üzerine PPI'lerin etkisi net bilinmemektedir. Hatta bazı çalışmalarda rivaroksaban alan hastalarda PPI kullanımının artmış gastrointestinal kanamayla ilişkisi bulunmuştur $(7,8)$.

Endoskopi kullanımının yaygınlaşması ile gastrointestinal tümörler arasında GNET görülme sıklığı artmıştır. En sık görülen Tip 1 GNET olup, \%70-80 asemptomatiktir ve genelde kadınlarda (\%70-80) görülür. Tip 1 GNET, otoimmün/kronik atrofik gastrit zemininde aklorhidri ve hipergastrinemi nedeniyle gelişmekte (9) ve PPI kullananlarda daha sık görüldüğü bilinmektedir. Atrofik olmayan gastrit zemininde PPI'ye bağlı GNET oluştuğunu gösteren olgu sunumları olduğu gibi (2), olgumuzdaki gibi PPI'nin önce atrofik gastrite yol açtığı, takibinde Tip 1 GNET gelişen olgular da mevcuttur. Hastamızın endoskopisinde atrofik korpus gastriti saptanmıştır. Bakılan Vitamin B12 seviyesi normal gelmiştir ve otoimmün gastrit açısından klinik şüphe olmadığı için intrinsik faktör (IF) ve antiparietal antikor (APA) bakılmamıştır. PPI ilişkili GNET düşünülen olgu sunumlarına bakıldığında da vitamin B12 düzeyi normal hastalarda bakılan IF ve APA'nın negatif olduğu görülmüştür (2). Ayrıca multipl endokrin neoplazi (MEN) 1 ve Zollinger-Ellison sendromu (ZES) gibi hastalıklar Tip 2 GNET olarak kendini göstermektedir. Hastamı Tip 1 GNET olduğu ve klinik şüphe olmadığı için MEN 1 ve ZES araştırılmamıştır. PPI kullanımı devam ettiği için gastrin seviyesi bakılmamıştır.

Asemptomatik olabileceği söylenmesine rağmen genelde benzer hastalarda dispeptik şikayetler ve kilo kaybı nedeniyle yapılan endoskopik biyopsi sonucunda tanı konmuştur $(2,5,6)$. Farklı olarak hastamızda dispeptik şikayetler mevcut değildi, endoskopisi anemi etiyolojisi için yapılmıştı.

GNET'in PPI bağlı olduğunu düşünmek için nöroendokrin hiperplazi nedenlerinden biri olan $\mathrm{H}$. Pylori enfeksiyon varlığı dışlanmalıdır. Hastamızın endoskopik biyopsisinde $H$. Pylori negatif saptanmıştır ancak bunun nedeni öncesinde $\mathrm{H}$. Pylori eradikasyonu yapılmış olması olabilir. Bununla birlikte uzun dönem PPI kullanımının nöroendokrin hiperplazi ile ilişkisini araştıran bir derlemede, $H$. Pylori enfeksiyonu varlığının GNET ile ilişkisinin olmadığını belirten yayınlar da mevcuttur. (5).

Sonuç olarak, gastrointestinal kanama açısından düşük riskli hastalarda PPI uzun dönem verilmemelidir. PPI kullanan hastaların her muayenesinde ilaç endikasyonu gözden geçirilmeli, dispeptik şikayetler nedeniyle kullanılıyorsa, tedavi etkili olan en düşük dozda verilmeli 
ve ikinci ayın sonunda anti-asit tedavi ile değiştirilmelidir. Proton pompa inhibitörlerinin, diğer ilaçların etki sürelerini arttırabileceği göz önünde tutulmalıdır. GNET Tip 1 genelde asemptomatik olduğu için tanıda gecikme olabilir ve buna bağlı kötü prognoz görülebilmektedir. Hastanın uzun dönem PPi kullanması gerekiyorsa, bu olgularda GNET gelişme olasılığı akılda tutulmalıdır.

\section{Kaynaklar}

1. Thompson W, Black C, Welch V, Farrell B, Bjerre LM, Tugwell P. Patient values and preferences surrounding proton pump inhibitor use: A scoping review. Patient 2018;11(1):17-28.

2. Cavalcoli F, Zilli A, Conte D, Ciafardini C, Massironi S. Gastric neuroendocrine neoplasms and proton pump inhibitors: Fact or coincidence? Scand J Gastroenterol 2015;50(11):1397-403.

3. Uygun A. Uzun süre proton pompa inhibitörleri (PPI) kullanılacaksa, hangi PPI tercih edilmelidir? Nelere dikkat edilmelidir? Güncel Gastroenterol 2013;17(1):46-58.

4. O'Mahony D, O'Sullivan D, Byrne S, O'Connor MN, Ryan C, Gallagher P. STOPP/START criteria for potentially inappropriate prescribing in older people: Version 2. Age Ageing 2015;44(2):213-8.

5. Lundell L, Vieth M, Gibson F, Nagy P, Kahrilas PJ. Systematic review: The effects of long-term proton pump inhibitor use on serum gastrin levels and gastric histology. Aliment Pharmacol Ther 2015;42(6):649-63.

6. Nandy N, Hanson JA, Strickland RG, McCarthy DM. Solitary gastric carcinoid tumor associated with long-term use of omeprazole: A case report and review of the literature. Dig Dis Sci 2016;61(3):708-12.

7. Chan EW, Lau WC, Leung WK, et al. Prevention of dabigatran-related gastrointestinal bleeding with gastroprotective agents: A population-based study. Gastroenterology 2015;149(3):586-95.

8. Sherwood MW, Nessel CC, Hellkamp AS, et al. Gastrointestinal bleeding in patients with atrial fibrillation treated with rivaroxaban or warfarin: ROCKET AF trial. J Am Coll Cardiol 2015;66(21):2271-81.

9. İnce AT, Tosun S. Gastroenteropankreatik nöroendokrin tümörler. Güncel Gastroenterol 2005;9(3):105-14. 